\title{
Diabetic compliance: A qualitative study from the patient's perspective in developing countries.
}

\author{
Mrs.Jansiraninatarajan,Msc(N), ${ }^{1}$ \\ I (Fundamentals and administrative Department, Sultan Qaboos University, Oman)
}

\begin{abstract}
Objectives: India faces an epidemic of T2DM and is referred as a diabetic capital of Asia (WHO2010). Compliance to therapeutic regimen in T2DM is a public health problem. Many studies have assessed the level of compliance, but the factors influencing compliance from patient perspective are remarkably absent. This paper reports about the motivating factors and barriers to therapeutic regimen from the perspectives of Type2DM patients of India. Research design and Methods: A qualitative study with in-depth interviews was conducted in 75 T2DM patients who had been diagnosed for at least 1 year prior to the study with no comorbidities using convenient sampling method attending a Multi-specialty tertiary hospital in Chennai, SouthIndia. Data collection and data analysis were conducted concurrently. The Audio-taped interviews were transcribed into verbatim. Each verbatim transcript was read several times, and the data were coded line by line. Codes were constantly compared with each other for similarity and dissimilarity and were grouped to form themes. Results: Three major themes and 9 sub-themes have emerged regarding their perspectives on the motivating factors and barriers from repeated coding. They are (1) Level of knowledge on causes, complications, treatment (2) Impact of Diabetes-psychological, social and (3) Compliance to treatment regimen-diet and nutrition, exercise, medications, self-monitoring and follow-up. They expressed acquiring knowledge, family support, lack of time and their emotions to be playing a greater role in their compliance towards therapeutic regimen. Conclusion: Because T2DM is a chronic illness requiring a variety of selfmanagement behaviors, a patient centered collaborative model of care recognizing patient autonomy provides a more skillful approach to improving their compliance.
\end{abstract}

Keywords - Type2Diabetes Mellitus, Compliance, therapeutic regimen, patient perspectives.

\section{INTRODUCTION}

Type 2 diabetes is a common and growing health problem worldwide. Diabetes mellitus (DM) is a syndrome characterized by many disorders where there is increased blood glucose concentration due to lack of insulin. Diabetes has serious long term implications not only for the individual but also on a global scale. There is no country in the world that does not bear some burden from diabetes. The IDF Diabetes Atlas Update for 2012 confirms that cases are increasing everywhere and at an alarming pace. Today, there are an estimated 371 million adults living with diabetes. To put this number into perspective: if all the people with diabetes formed a country, it would be third largest in terms of population after China and India. Four out of five of the people with diabetes live in low and middle-income countries, where health systems are struggling to keep pace with the growing burden of non-communicable disease. ${ }^{1}$

The human and economic toll of diabetes mellitus particularly type 2 diabetes is likely to grow globally in the foreseeable future due to rapid cultural changes, aging population, increasing urbanization, dietary changes, decreased physical activity and other unhealthy lifestyle and behavioral patterns. According to international diabetes institute in Australia, India has been estimated to have 32.7 million people with diabetes. The prevalence was 31 millions in India during 2000 which is expected to reach 79 Million by 2030 (WHO, 2005). ${ }^{2}$

Since diabetes is a chronic disease the patients with diabetes must learn to co-ordinate the treatment regimen. The diabetic patient is ultimately responsible for managing his or her own care and to prevent complications, he or she must have adequate knowledge and other facilitating factors towards compliance to therapeutic regimen. Type2DM needs therapeutic control, generally involving strict, rigorous and permanent lifestyle changes that include dietary interventions, physical activity, strict medication regimes and good metabolic control.

The rate of non-compliance in patients with chronic diseases in developed countries, on long-term treatment, is on the order of 50\%. This could be even higher in developing countries (WHO-2010). ${ }^{3}$ Noncompliance can be due to factors that are patient-centered, therapy-related, or healthcare system -related. The patient-centered factors can be demographic (age, gender, educational level, and marital status) and psychological (patients' beliefs and motivation towards the therapy, negative attitude, patient-prescriber relationship, understanding of health issues, and patient's knowledge). The therapy-related factors include route 
of medication, duration of treatment, complexity of treatment, and the side effects of the medicines. The factors associated with the healthcare system include availability, accessibility, and the physician.

Usually diabetic patients in India are not prepared adequately for self care. These patients often find it sufficient to take care of themselves at home, with very little medical accessories. The poor economic background is an obstacle for getting continuous therapy. Ignorance and in-adequate medical facilities are some of the other contributing factors. Unlike other diseases, diabetes is not painful, this make the patients complacent and only when they are hospitalized do they wake up to the hard reality. The findings from the recently published CrossNational Diabetes Attitudes, Wishes, and Needs (DAWN) Study showed patient-reported adherence rates for medication in type 1 and type 2 diabetic patients of 83 and 78\%, respectively; SMBG adherence was 70 and $64 \%$, respectively; and appointment keeping adherence was 71 and $72 \%$, respectively. The adherence rates observed for diet for type 1 and type 2 diabetic patients were 39 and 37\%, respectively, and for exercise they were 37 and 35\%, respectively. Providers reported significantly better adherence for type 1 than for type 2 diabetic patients across most regimen domains. ${ }^{4}$

From the Medco Study on Diabetic Non-Compliance, 2005, Dr. Robert Epstein reports that the least compliant diabetes patients were more than twice as likely to be hospitalized compared to those who were most compliant, and their total health-care costs were nearly double. The study notes that people who use their diabetes medications as directed are less likely to develop the short-term and long-term health problems that can require expensive care. ${ }^{5}$

A Systematic Review of Adherence with Medications for Diabetes was conducted by Joyce A. Cramer in 2004 which confirms that many patients for whom diabetes medication was prescribed were poor compliers with treatment, including both OHAs and insulin. ${ }^{6}$

Non-compliance is a problem among Indians. They want the doctor and the drug to control them, though in this disease, the treatment lies in the patient's co-operation. A clinic based descriptive (case series) study was conducted by Battacharya and team in 2005 among 106 study subjects with poor glycaemic control in a tertiary care hospital, Kolkata. Poor compliance was observed in $89.62 \%$ and $10.38 \%$ had good/acceptable compliance. Compliance was better in above 60 years age group, in males, in married and educated persons. ${ }^{7}$

Watkins et al. reported that $80 \%$ of the patients studied, administered their insulin in an unacceptable manner, $73 \%$ did not adhere to their diet plans, 50\% did not engage in proper foot care, $67 \%$ did not correctly test their urine, and $45 \%$ tested and used the results in a manner likely to be detrimental to their diabetic control. ${ }^{8}$ Williams et al. found that approximately $50 \%$ of their diabetic subjects always displayed significant deficits in their food intake. More-recent studies have reported rates of regular urine testing as low as $30 \%$ and dietregimen compliance in the $10-35 \%$ range. ${ }^{9}$ In perhaps the most detailed examination of adherence to different aspects of the treatment plan, Cerkoney and Hartl obtained compliance levels of $81 \%$ for insulin administration, $77 \%$ for foot care, $65 \%$ for diet, and $57 \%$ for urine testing (only $7 \%$ of patients complied with all the steps considered necessary for good control). ${ }^{10}$

Because of the chronic nature of disease patients with diabetes require lifelong compliance with treatment regimen. Compliance is only through adherence to a prescribed plan of care so that blood glucose levels may be kept within the normal range. Poor compliance is an important health care problem, which can result in reduced efficacy or failure of the recommended intervention, with detrimental effects on the patient's health. There are numerous factors which may impair the compliance to adequate nutrition, exercise and medication among patients with diabetes.

The bio-psychosocial construct acknowledges that disease results from a dynamic interaction among biological, psychosocial, developmental, socio-cultural and ecological factors. Not only are individual influences important in the management of diabetes, but environmental influences affects the preventive and curative behaviors. These dynamic inter-reactions occur in varying proportion throughout life.

Psychological factors are also linked with regimen adherence. Appropriate health beliefs, such as perceived seriousness of diabetes, vulnerability to complications, and the efficacy of treatment, can predict better adherence. ${ }^{11}$ Patients adhere well when the treatment regimen makes sense to them, when it seems effective, when they believe the benefits exceed the costs, when they feel they have the ability to succeed at the regimen, and when their environment supports regimen-related behaviors.

As the incidence of diabetes is on the rise, it is important that nurses assess the patient's understanding of the disease and treatment and compliance to it. This study intends to explore the factors influencing compliance to therapeutic regimen, with the aim to understand the motivating factors and barriers and thereby formulate strategies to build up compliance among T2DM patients.

\section{Methodology:}

This qualitative, descriptive, exploratory study consisted of open-ended questions designed to motivate the participants to reflect upon factors associated with compliance towards their therapeutic regimen. Participants for this study were 75 Diabetic patients obtained by using Non-probability convenient sampling, attending OPD 
at VHS hospital, Chennai.VHS is a tertiary care Multi-specialty hospital situated in the heart of this Metropolitan city, Chennai, India. Both male and female patients who are diagnosed to have Type 2 diabetes mellitus for more than one year and up to 10 years with no co-morbidities were chosen to be the participants with their written informed consent. The minimum age of eligibility was 35 years and participation was limited to the informants who agreed to be interviewed in English or Tamil. Interviews were conducted face-to-face to uncover their experiences. Interviews averaged approximately 30-45 minutes in length. All interviews were Audio- taped with the permission of the participants, and then transcribed, segmented and coded.

The tool used was a semi-structured interview guide prepared by the investigator which consisted of two sections. Section A, Consisted of questions to elicit demographic variables and Section B Consisted of open ended questions to explore the factors influencing compliance to therapeutic regimen. The questions were categorized under the following headings: 1 . Knowledge aspect. 2. Perceptions about the factors influencing compliance to the treatment regimen pertaining to: Diet, Medications, Exercise, Follow up care. The tool used in this project was validated by Diabetologists and experts in the field of Medical Surgical Nursing.

The study proposal was reviewed and approved by the ethical committee of M. A. Chidambaram College of Nursing, Chennai.

Data Analysis: Data gathered from the transcription of the interviews were organized by individual questions with the corresponding verbatim answers from the participants. The responses were coded line by line to find commonly used words or descriptions of experiences, which were labeled to characterize the answers and develop them into Themes and sub-themes and provide illustrative quotations reflecting these themes. This involved a number of stages: First the interviews were transcribed to revise and examine them for common and recurring themes and sub-themes. Stage two involved further organization of the themes primarily by focusing on responses to a particular question. Tables were created to report Demographic information.

\section{Results:}

The main baseline and demographic characteristics of the patients are presented in Table 1. Finding shows that the majority (35\%) of the diabetic patients were in the age group of 51-60 years; 55\% of them were females; $31 \%$ were illiterate; $33 \%$ of them have attended up to primary school and only $5 \%$ of them were graduates. Regarding their occupation $33 \%$ of them were un-employed and $27 \%$ of them were retired and the majority (79\%) was Hindus by religion.35\% of them had monthly income between Rs1001-3000/-.

$84 \%$ were non-vegetarians. $76 \%$ of them did not have any habits of smoking and alcoholism. With regard to their duration of illness $47 \%$ of them were having diabetes between one and three years. $43 \%$ of them came for checkup once in a month where as $16 \%$ came only when they felt tired or sick.

The data used in the analysis are transcriptions of the taped interviews. Thematic analysis of these topic codes was used to identify and describe the major issues in each of the topic areas. The themes were identified on the basis of keywords and phrases and were modified as each interview was examined. The identified themes were interpreted with respect to $\underline{3 \text { major themes and } 9 \text { sub-themes. }}$.

\section{Theme: 1- Level of Knowledge:}

Sub-themes:

a) Causes:

Illness was generally attributed to events or agents outside the body rather than to primary failure of an organ within it. Many informants believed that the primary cause of diabetes, and that of poor diabetic control, was too much sugar. Other etiological factors mentioned by the informants included heredity, sedentary lifestyle and obesity. Some informants mentioned physical or psychological stress, either as a perceived cause of diabetes. Very few informants felt that it was because of less insulin secretion. Also some said that it was because of eating more sweets and polluted city lifestyle.

\section{b) Complications:}

Majority of the informants could express that the disease can damage their vital organs in the body. Few even declared that they do not know anything about the complications.

\section{C) Treatment of Diabetes:}

Half of the participants expressed that diet, medications and exercise are important in treating diabetes. Few of them indicated that diet and medications alone could reduce the blood sugar levels. The rest were not sure of anything. 


\section{Theme: 2- Impact of Diabetes:}

\section{Sub-themes:}

\section{a. Psychological impact:}

The in-depth interviews showed that diabetes affected the T2DM patients' physical, emotional and social life. Psychosocial distress has been found to impact negatively on patients with regard to initiating and maintaining recommended self-care. This was confirmed by participants of the present study, who repeatedly cited the psychological and emotional stress they experienced as a result of diabetes as impeding their management and compliance with the treatment regime.

Many emphasized that they had not experienced 'shock' when diagnosed. "I did accept it because I thought well it was something that would-could possibly happen later on." Others implicitly or explicitly suggested that, although they had experienced negative emotions like crying, mourning on hearing their diagnosis, this was short lived. Many informants felt that they ventilated their emotions sometimes negatively on their family members or neighbors like quarreling, shouting or even beating the wife or children. Some informants said "I kept it to myself". Few others said "I prayed to God".

The diagnosis of diabetes was generally seen as devastating, and the expression, "I was spoiled" was used by several informants. Virtually all felt that diabetes was a chronic, incurable condition and a potential threat to life. They feared acute complications (Collapse and "dropping dead") and therefore reduction in disability and prolongation of life was felt to lie in restoring the body's internal balance via taking particular foods and reducing the sugar levels with medicine.

This reflects the need to develop counseling sessions and the need to emphasize relaxation techniques like meditation, yoga, music therapy etc.

\section{b. Social impact:}

Few informants shared their views as they are happy and satisfied about the support from family and friends in following a recommended meal plan, medications, foot care and diabetic monitoring. Majority of the informants expressed their difficulty in spending money for treatment. Most of the informants said that they are not able to travel or visit their relatives and friends like before. ("As much as I want")

\section{Theme: 3- Compliance to treatment:}

\section{Sub-themes:}

\section{a) Diet and Nutrition:}

Many informants believed that the same amount of rice could be taken but as frequent small meals. Most of them agreed on the importance of following the recommended meal plan. Many informants expressed their difficulty in following a particular diet plan during their visits with family and friends. Some also said that they felt uncomfortable eating a different meal from the rest of the family. Few even stated that lack of family support, i.e., "my daughter-in-law refuses to cook separately for me with less oil". Most of them felt that the taste decreases when restrictions are followed in the meal plan. Some of them even expressed that it is hard to control their food intake. ("I am a big rice eater"). One informant said that "I need to fill my stomach with food for me to work." Some informants even expressed that "It is difficult to change my pattern of eating from rice to wheat items." Difficulties in managing the social elements of meals were intensified in ritual meals like weddings, birthdays and Festivals.

\section{b) Exercise:}

Exercise in the context of health and fitness seemed to have little meaning for the informants, though they often recalled specific advice on this topic from the health personnel. Exercise was viewed as potentially exacerbating the illness or causing physical weakness. Most of them believed that it was necessary. Some of them felt that they are too busy to do exercise in the morning. Some of them said that it is enough to do only the household activities. Some informants gave physical constraints like leg pain, knee joint pain to taking exercise. Some informants felt going for walking alone is enough. One informant even mentioned that laziness especially during winter season was a barrier for regular exercise. Lack of self motivation and lack of time for exercise were also expressed by few of the participants.

\section{c) Medication:}

Few informants felt that taking medications is not very important in the management of diabetes. The younger age group (35-40 Yrs) patients perceived significantly fewer barriers to taking medications. Many informants felt that it is costly to get medications regularly. Some informant said that "sometimes I forget to take medicine in my busy work schedule". Few other informants even said that "if I have skipped one dose in the day, I compensate it in the night". Very few expressed that they did not take medicines whenever they experienced side-effects. 


\section{d) Diabetic self monitoring and Follow up visits:}

Diabetic self monitoring was only a new concept for all of them. Majority of the Informants generally tested their urine and blood sugar in the hospital regularly, and all who did so seemed to have understood the importance of a change in that to some extent. Many of the participants depend on the health care providers to reveal the meaning of the results. Majority of the informants felt that the seriousness of diabetes, vulnerability to complications and the efficacy of treatment as their motivating factor of preventive self-management. Preventive care was not well understood. Several informants felt that it is usually very difficult to keep up with the appointments because of financial constraints, distance from the hospital, need for dependency on others, work schedule etc. Some young informants said that they want to lead a happy life by preventing complications which is motivating them to come for regular check-ups.

\section{Discussion}

This study briefly explored the factors influencing compliance to therapeutic regimen among patients with diabetes mellitus. This study addressed an important area in health care, non-compliance being a major problem in public health among diabetic patients.

Diabetes is a chronic disease of lifelong duration, and its management requires a fundamental change in the patient's lifestyle. For example, Diet therapy is essential in the treatment of all forms of DM and patient is instructed to follow the diet permanently even when there are no symptoms. Adherence to this regimen is essential to reach and maintain ideal body weight, proper nutrition, control blood glucose and lipid levels and prevent long and short term complications (Cramer, 2004). ${ }^{6}$

There is limited information on the factors influencing compliance towards the therapeutic regimen among diabetic patients. Many factors have an effect on glycemic control in diabetic patients. Depression, cognitive functioning, diabetes knowledge, family support, exercise, dietary habits, lifestyle, treatment regimens, and access barriers are some of the potential predictors of glycemic control in diabetic patients, said Prof. M Vishwanathan(2003). ${ }^{12}$

The analysis of this study resulted in three major themes emerging on level of knowledge, impact of diabetes, and compliance to therapeutic regimen and 9 sub-themes. Diabetic patients admitted that they have an inadequate and incomplete knowledge about the disease but were eager to know more. Findings of the study revealed that knowledge about preventive aspects of complications was very less. For some of them knowledge about overall diabetic care was inadequate. Several informants in the study stated that they had never received any structured teaching about diabetes. And all these were considered as barriers for their compliance to therapeutic regimen. Patients' lack of knowledge about diabetes care can impede their ability to manage their disease. This is important as better patient self-management ability is related to improved diabetes control. The informants emphasized the importance of lifestyle in disease causation were more likely to identify lifestyle as an important aspect of disease management and themselves as responsible for managing the emotions. This highlights the need for creating good awareness on self care aspects of diabetes. This study supports the findings of Snoek (2002) which showed a widely accepted view among the health care professionals that patients need to be aware that type II diabetes is a potentially serious disease, as this awareness through structured teaching program may facilitate motivation and commitment to comply with diabetic regimens. ${ }^{13}$ Efforts focused on DM patients are needed to encourage greater compliance. Regular education of patients with DM is an important strategy which may lead to improved compliance and better quality of life (Glasgow et al, 2005).$^{14}$ Implementation of structured care including education and therapeutic advice can result in sustained good glycaemic control in these diabetic patients with low risk of hypoglycemia.

In this study compliance with follow-ups and drugs was much better than compliance with diet. This concurs with the findings of Ghotekar and Meena (2000) where it has been observed that compliance is better with medical aspects of a regimen like medication than with lifestyle aspects of a regimen such as diet and exercise. ${ }^{15}$

For many informants dietary non-compliance was related to self-care abilities, lack of knowledge and lack of family support in preparing therapeutic meal plans. Dietary restrictions on carbohydrates can be particularly challenging to a population that has historic, symbolic and ritualized inclusion of rice in their daily diets. With the help of dietitians, prescribing a diabetic diet that balances rice with vegetables and proteins is more culturally sensitive.

Men were more compliant to exercise compared to women. For some of them it was age related physical constraints like joint and leg pain which acted as barriers in doing exercises and coming for regular checkups. Several Informants in the study perceived that exercise was not important for controlling their diabetes. They were not well informed about other types of exercises than walking. These difficulties were also reported as barriers by Epstein et al. (2004). ${ }^{16}$ Getting patients to manage time more effectively and to work around practical constraints, to devote sometime to exercise is a worthwhile objective. 
Generally higher levels of compliance to medical aspects of treatment (e.g. Medication and glucose testing) demonstrate that most of the informants were motivated to follow their treatment despite multiple barriers like low socio-economic background. Younger age group perceived fewer barriers to taking diabetes medications than older age group. Most of them expressed financial difficulties and burden in buying the medications and spending for follow up care. Some of them missed on medications and exercise schedule because of the busy work schedule. This coincides with the findings of the literature review of twenty studies by Joyce Cramer of Yale University School of medicine (2004), concluded a large population of diabetic patients has difficulty managing their medication regimens reporting cost problems. ${ }^{6}$ This highlights the need for identifying and mobilizing financial sources for helping these patients. An encouraging approach to caring for people with diabetes helps to build self confidence and freedom.

Positive health beliefs and attitudes and interaction with health care professionals are motivating factors for many informants. Praise and encouragement from health care professionals was identified as an important motivating factor in accounts where respondents identified lifestyle behavior as an important part of disease management. Information provision is especially salient for type2diabetic patient management. It is well accepted as a central component in making patient participation effective. The link between knowledge about diabetes management and subsequent compliant behavior is evident in many research findings.

It is well established that people do not change behavior from information or knowledge alone (Hibbard, Peters, Dixon, \& Tusler, 2007; Nutbeam, 2006; Rapaport et al., 2000). ${ }^{17}$ This was born out in this study, indicated by patients' reliance on the health care provider to tell them what they need to do, the ambivalence in accepting the diagnosis, and the difficulty of maintaining the lifelong regimen of managing diabetes. These responses show how emotions affect treatment compliance and disease self-control. Few other Informants have negative attitude about coping with their illness and could not comply with the treatment. Few even felt that family and social support was lacking in complying with the treatment regimen. The recent DAWN study showed that a significant number of diabetic patients have poor psychological well-being and that providers reported that these psychological problems adversely affected regimen adherence. ${ }^{18}$ The impact of diabetes is all-encompassing and its effects on daily life, work life and social relationships represent a significant impairment of quality of life.

The treatment of diabetes requires permanent changes in the life of the person with diabetes. It may arouse emotions such as fear, guilt, shame, anger, weariness, and regret (Peres, Franco, \& Santos, 2008). ${ }^{19}$ Such feelings, if present, affect daily treatment and decision making that includes complying with basic recommendations and self-care management.

In this study social support was a significant predictor of patients' compliance to diet. Acknowledging the multiple and competing social concerns being managed by the patients and families provides an opening for discussion and problem solving with the health care provider. Family members could be encouraged to help them in changing certain lifestyle factors like dietary restrictions. This further emphasized the need for educating the family members regarding diabetes.

As Aitken and colleagues note, there may be pragmatic constraints on lifestyles imposed on by diet such that many individuals may feel disconnected. ${ }^{20}$ Indeed, for some participants the awkwardness was sufficient for them to avoid social gatherings altogether; others felt pressured to ignore their dietary restrictions and risk their health instead. Participants experienced feelings of being isolated and excluded and reported curtailing their social life for fear that people around them might not understand them and their problem.

Gleeson-Kreig (2008) asserts that the social context of living is important to diabetes management. ${ }^{21}$ Controlling diabetes does not rest only with the individual but is influenced by the family and community in which the person lives.

Family relationships play an important role in diabetes management. Studies have shown that low levels of conflict, high levels of cohesion and organization, and good communication patterns are associated with better regimen adherence. Greater levels of social support, particularly diabetes-related support from spouses and other family members are associated with better regimen adherence. Social support also serves to buffer the adverse effect of stress on diabetes management. ${ }^{22}$

Finally some of the participants combined the intake of medicines along with bitter gourd, Fenugreek powder and sirukurinji greens without the knowledge of health care professionals. Simultaneous use of home remedies with medication has been found in other studies (Kay 1977, Jackson., 1981). ${ }^{23}$, ${ }^{24}$ Further in their extensive literature research, Bailey \& Day (1989) have concluded that some plants have hypoglycaemic effects. ${ }^{25}$ Several of them took alternative remedies as recommended by their social net works and without the knowledge of the diabetes care team. More research is needed in this aspect to establish the effect of complimentary therapies in improving glycemic control. Nurses must be able to elicit information about the use of these remedies from their patients in a sensitive, culturally competent, and nonjudgmental manner.

Diabetes must be understood from the psychological, spiritual, and behavioral as well as the medical perspective (Peres et al., 2008). ${ }^{26}$ Health care providers must understand behavior change as part of an 
interpersonal process. Although patients are responsible for their own decisions and self-care behaviors, patient outcomes are also affected by health care provider behaviors. ${ }^{27}$

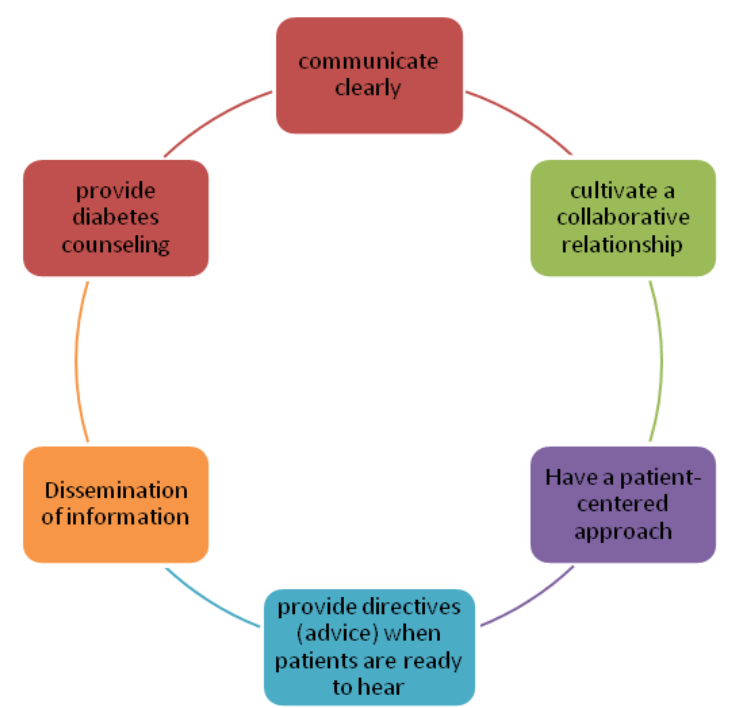

Fig.1: Strategies for improving Diabetic compliance:

Nurses should focus on providing people with diabetes with the necessary cognitive, social, and practical skills needed for autonomously exercising of self-management. ${ }^{27,28}$

Hence, rather than designing an education program to be delivered externally to reach by "deficiencies" in knowledge or "incorrect" behavior, the researcher suggests that health promotion program attempting to build on those beliefs, attitudes and behaviors that already exist within their culture can promote good diabetes control. This in-turn can prevent complications and improve quality of life of these T2DM patients.

\section{Nursing Implications:}

Nurses being the liaisons between people with diabetes and health care professionals, play a vital role in enhancing patient's participation in the self care program on diabetes. By putting forward information related to self care practices in a meaningful and manageable manner nurses can help patients to develop control over their illness and therefore comply with treatment regimens. Understanding of the health locus of control concept and its association with benevolent powerful others would enable nurses to mobilize the social support resources and strengthen them to provide support for the persons with diabetes.

Continuing education on current approaches like Patient-Centered model of care and holistic approach could provide up to date information for nurses working in the hospitals.

Comparative study may be conducted to find out similarities or differences between knowledge and treatment compliance of urban and rural diabetic patients. Experimental research to see the effect of nursing interventions such as targeted individual teaching, group session, diabetic camps, and stress coping mechanism on the locus of control can be done. A comparative study can be conducted to identify the differences in factors influencing the compliance in male and female diabetic patients.

\section{Conclusion}

In India, as in other countries, the health system has traditionally been designed to cater to acute illness and maternal and child health concerns. The burgeoning load of diabetes is a real threat in India, underscored by the constraints of the health system in terms of manpower and capacity. ${ }^{29,30}$

In conclusion, it is worthwhile to say that this analysis has identified the factors to improve the compliance among diabetic patients and the patients require more ongoing teaching on self care practices. This may shift the locus of control from external to internal. The patients would feel more at ease with the complexity of living with their disease if the health care provider can attempt to identify and discuss their issues on compliance. The health care personnel must constantly support, inspire, and teach, guide and counsel patients regarding their illness. The long-term relationship of patients with their diabetes requires compromise over a lifetime.

\section{Limitations:}

A limitation of this study is that, the interviews took place within a geographical area. 


\section{Conflict of interest:}

The author declares that she has no conflict of interest.

\section{Acknowledgement:}

The author thanks all the people with T2DM who were willing to spend time for interviews and share their experiences. She also would like to thank the staff of VHS Diabetic OPD for their appreciated support in the data collection

She also would like to thank DR.C.V. KRISHNASWAMI, FRCP (E) D.T.M. \& H (EDIN) FAMS Head Of The Diabetes Department, VHS Medical Centre, Mrs. AMBIKA RAVINDRAN, Principal and Professor of Nursing, Prof. Hannah Victor, Vice principal, MRS. UMA RAGHU., M.Sc. (N) R.N.R.M. Professor in Nursing M. A. Chidambaram college of Nursing, Chennai, India, who have played a vital role as medical expert and research guides for the successful completion of this research venture. She is indebted to Dr.Vidhya Seshan, Lecturer in college of nursing, Sultan Qaboos University, for her helpful discussions, support, and reviews of the manuscript.

This study was not funded by any organization.

Jansi Rani Natarajan, holds a Masters Degree in Medical Surgical Nursing from M. A. Chidambaram College of Nursing, Chennai, South India. She has served as a registered nurse in the Medical and Surgical wards for 3 years after her Baccalaureate degree. Thereafter she has been placed in various academic positions in Nursing Education. She has served as a research guide for a period 3 years $(2009-2012)$. She is currently working as a lecturer at Sultan Qaboos University.

\section{References:}

[1]. Diabetes Epidemic out of Control, Press release, International Diabetic Federation. 2006. Dec, [Last accessed on 2010 Sep 2]. Available from: http://www.IDF

[2]. World Health Organization: Report on Medication Adherence. Geneva, World Health Org., 2005 World Health Organization. What is diabetes? http://www.who. int/mediacentre/factsheets/fs312/en/print.html. Published September 2006. Accessed September 10 2008 .

[3]. WHO: A report; Chronic Diseases - Poor compliance of Patients with drug treatment[online] [Last cited on 2010 Oct 02]Available from: http://www.bio-medicine.org/medicine-news/In-Chronic-Diseases---Poor-compliance-of-Patients-with-drug-treatment--2097-1

[4]. Peyrot M, Rubin RR, Lauritzen T, Snoek FJ, Matthews DR, Skovlund SE: Psychosocial problems and barriers to improved diabetes management: results of the Cross-National Diabetes Attitudes, Wishes and Needs (DAWN) Study. Diabet Med 22:1379 -1385, 2005

[5]. Medco Study on Diabetic Non-Compliance, 2005, Epstein, Robert MD. http://www.hreonline.com/HRE/story.jsp?storyId=5059249

[6]. Joyce A Cramer "A systematic review of adherence with medications for diabetes." Diabetes Care 20041218 - 1224

[7]. Bhattacharya N.etal "A study of compliance status of diabetic patients" Indian journal of public health , Jan - Mar 2005; 49 (1) 34-35

[8]. Watkins, J.D., Williams, T.F., Martin, D.A., Hogan, M.D., and Anderson, E. A study of diabetic patients at home. American Journal of Public Health, 1967, :5452-7459.

[9]. Williams, T.F., Anderson, E., Watkins, J.D., and Coyle, V. Dietary errors made at home by patients with diabetes. Journal of the American Dietetic Association, :151996-1275,

[10]. Cerkoney, K.A.B., and Hart, L.K. The relationship between the health belief model and compliance of persons with diabetes mellitus. Diabetes Care, 1980, 3:594-598.

[11]. Jayendra H Shah, Glen H Murata, William C Duckworth, Richard M Hoffman, Christopher S Wendel, " Factors Affecting Compliance In Type 2 Diabetic Patients: Experience From The Diabetes Outcomes In Veterans Study (Doves)", Int. J. Diab. Dev. Countries (2003), Vol. 23

[12]. Viswanathan V, Shobhana R, Snehalatha C, Seena R, Ramachandran A. Need of education on foot care in diabetic patients in India. J Assoc Physicians India. 1999;47:1083-5. [PubMed: 10862318]

[13]. Snoek.F.J "Breaking the barriers to optimal glycemic control " International journal of clinical practice 2002; $129 \quad 80-84$

[14]. Glasgow, R., Toobert, D., Barrera, M., Jr., \& Strycker, L. (2005). The chronic illness resources survey: Cross-validation and sensitivity to intervention. Health Education Research, 20(4), 402-409.

[15]. Epstein et al,(2004) Multiple Behavior Changes in Diet and Activity: A Randomized Controlled Trial Using Mobile Technology .Arch Intern Med. 2012;172(10):789-796.

[16]. Hibbard, JH, Mahoney E, Stock R, Tusler M. Do Increases in Patient Activation Result in Improved Self-management Behaviors? Health Services Research. 2007; 42(4):1443-63.

[17]. Peyrot M, Rubin RR, Lauritzen T, Snoek FJ, Matthews DR, Skovlund SE. Psychosocial problems and barriers to improved diabetes management: results of the Cross-National Diabetes Attitudes, Wishes and Needs (DAWN) Study. Diabetic Medicine 2005; 22:1379- 1385. $2010 \mathrm{Feb} ; 108(2): 88-90$.

[18]. Peres DS, Santos MA, Zanetti ML, Ferronato AA(2008). Difficulties of diabetic patients in the illness control: feelings and behaviors. Revista Latino-Americana de Enfermagem 15(6):1105-12.

[19]. Coffey, A., \& Atkinson, P. (1996). Making sense of qualitative data: Complementary research strategies. Thousand Oaks, CA: Sage Publications.

[20]. Gleeson-Kreig, J. (2008). Social support and physical activity in type 2 diabetes: A social-ecologic approach. The Diabetes Educator, 34(6), 1037-1044.

[21]. Kay, Margarita 1977 Health and Illness in a Mexican American Barrio. In Ethnic Medicine in the Southwest. Edward Spicer, ed Pp.99-166. Tucson: University of Arizona Press.

[22]. Jackson, R. L., Hess, R. L. r and England, J. D.: Hemoglobin Al c values in children with overt diabetes maintained in varying degrees of control. Diabetes Care 2; 391 - 95 , 1979.

[23]. Bailey, C. J., \& Day, C. (1989). Traditional plant medicines as treatments for diabetes. Diabetes Care, 12, 553-564.

[24]. Egede, L. E., Ye, X., Zheng, D, \& Silverstein, M. D. (2002). The prevalence and pattern of complementary and alternative medicine use in individuals with diabetes.Diabetes Care, 25, 324-329. 
Diabetic compliance: A qualitative study from the patient's perspective in developing countries.

[25]. Choc.S.J. etal "A study on the socio psychological factors influencing the dietary compliance of diabetics " Korean Journal of community nutrition 2000 March ; 5 (1) 23-25

[26]. J.S.Chatterjee "From compliance to concordance in diabtes" Journal of Medical Ethics 2006;32 507-510

[27]. Marshall H.Becker and Louise A Maiman ,"Strategies for enhancing patient compliance" Journal of Community Health April 2005 Vol 6 No.4 113-135

[28]. Joslin Diabetes Center. Growing diabetes in Asians [article online], 2002. Available at http://www.joslin.org/1083 2004.

[29]. Wild S, Roglic G, Green A, Sicree R, King H: Global prevalence of diabetes. Diabetes Care 2004, 27:1047-1053., Mart, T.F., Anderson, E., Watkins,

\section{TABLE.1-Frequency and percentage of Demographic variables of the samples:}

\begin{tabular}{|c|c|c|c|}
\hline \multicolumn{4}{|c|}{ DEMOGRAPHIC VARIABLES } \\
\hline S.No. & Demographic Variables & Frequency & Percentage \\
\hline \multirow[t]{6}{*}{1} & Age & & \\
\hline & $30-40$ Yrs. & 12 & 16 \\
\hline & 41-50 Yrs & 17 & 23 \\
\hline & $51-60$ Yrs & 26 & 35 \\
\hline & $61-70$ Yrs & 15 & 20 \\
\hline & 71-80 Yrs & 5 & 7 \\
\hline \multirow[t]{3}{*}{2} & Sex & & \\
\hline & Male & 34 & 45 \\
\hline & Female & 41 & 55 \\
\hline \multirow[t]{6}{*}{3} & Educational Status : & & \\
\hline & Illiterate & 23 & 31 \\
\hline & Primary & 25 & 33 \\
\hline & High School & 17 & 23 \\
\hline & Higher Secondary & 6 & 8 \\
\hline & Graduation and Above & 4 & 5 \\
\hline \multirow[t]{8}{*}{4} & Occupation: & & \\
\hline & Employed & & \\
\hline & Labourer & 14 & 19 \\
\hline & Executive & 5 & 7 \\
\hline & Houemaid & 9 & 12 \\
\hline & Business man & 2 & 3 \\
\hline & Un-employed & 25 & 33 \\
\hline & Retired Person & 20 & 27 \\
\hline \multirow[t]{5}{*}{5} & Religion & & \\
\hline & Hindu & 59 & 79 \\
\hline & Christian & 13 & 17 \\
\hline & Muslim & 2 & 3 \\
\hline & Others & 1 & 1 \\
\hline \multirow[t]{6}{*}{6} & Marital Status: & & \\
\hline & Un-married & 1 & 1 \\
\hline & Married & 49 & 65 \\
\hline & Widow & 22 & 29 \\
\hline & Divorcee/Separated & 22 & 29 \\
\hline & & & 0 \\
\hline \multirow[t]{5}{*}{7} & Monthly Family Income: & & \\
\hline & below Rs.1000/- & 20 & 27 \\
\hline & Rs1001-3000/- & 26 & 35 \\
\hline & Rs3001-6000/- & 18 & 24 \\
\hline & Above Rs.6000/- & 11 & 15 \\
\hline
\end{tabular}


Diabetic compliance: A qualitative study from the patient's perspective in developing countries.

\begin{tabular}{|c|c|c|c|}
\hline 8 & Dietary habits: & & \\
\hline & Pure Vegetarian & 11 & 15 \\
\hline & Egg-Vegetarian & 1 & 1 \\
\hline & Non-vegetarian & 63 & 84 \\
\hline \multirow[t]{6}{*}{9} & Personal Habits: & & \\
\hline & Smoking & 5 & 7 \\
\hline & Alcoholism & 7 & 9 \\
\hline & Betel nut/Tobacco chewing or panparag & 5 & 7 \\
\hline & None of the above & 57 & 76 \\
\hline & Smoking and Alcoholism & 1 & 1 \\
\hline \multirow[t]{7}{*}{10} & $\begin{array}{c}\text { Do you have any family members with } \\
\text { diabetes? }\end{array}$ & & \\
\hline & Mother/Father & 12 & 16 \\
\hline & Grandmother/Grand Father & 0 & 0 \\
\hline & Brother/Sister & 12 & 16 \\
\hline & Nobody had diabetes & 43 & 57 \\
\hline & Do not know & 5 & 7 \\
\hline & Parents and Siblings & 3 & 4 \\
\hline \multirow{4}{*}{11} & How long are you having Diabetes? & & \\
\hline & $1-3$ Years & 35 & 47 \\
\hline & 4-6 Years & 18 & 24 \\
\hline & 7-10 Years & 22 & 29 \\
\hline \multirow[t]{6}{*}{12} & Frequency of health check up: & & \\
\hline & Once in a week & 2 & 3 \\
\hline & Once in a Month & 32 & 43 \\
\hline & Once in 3 months & 24 & 32 \\
\hline & Once in 6 months & 5 & 7 \\
\hline & Whenever feels tired or sick & 12 & 16 \\
\hline
\end{tabular}

